\title{
Potensi Penerapan Konsep Zero Waste Pada Busana Tradisioanal Studi Kasus: Kimono
}

\author{
Faradillah Nursari, Dian Fitrah Hervianti \\ Universitas Telkom
}

\begin{abstract}
Zero waste is a concept commonly used in the manufacturing industry in order to reduce the pre-consumer waste that occur during production phase. This concept was later adopted in the fashion industry to minimize left-overs or scraps when cutting patterns pieces on fabric. Unknown to most, this concept was actually used by our ancestors to create traditional clothes in the simplest form. Geometric shape is one of the simplest form of clothing adopted in many cultures for their traditional clothes. This shape can be seen in most Asian cultures, one of them is Japan. Kimono, Japanese traditional clothes, is one example of adapting the geometric shape for clothing purposes. Constructed from a basic rectangle shape made of fabric that is woven traditionally, it has many potential to evolve in terms of construction and production method, furthermore, having the possibility of being more sustainable by applying the zero waste concept.
\end{abstract}

Keywords: Zero Waste, Fashion, Kimono.

\section{PENDAHULUAN}

Industri tekstil dan fashion merupakan salah satu sektor ekonomi terbesar di Indonesia, didukung oleh semakin tingginya minat masyarakat terhadap produk fashion dalam maupun luar negeri dan sirkulasi tren yang semakin dinamis setiap tahunnya. Segmentasi produk tekstil dan fashion yang semakin beragam, dimulai dari batik hingga busana muslim, turut mendukung percepatan ekonomi dan industri kreatif di Indonesia. Salah satu perkembangan yang signifikan dapat dilihat dari semakin banyaknya industri garmen dalam negeri yang aktif membuat produk fashion untuk berbagai merek dengan jenis produk yang beragam untuk dipasarkan di dalam dan luar negeri. Dengan berkembangnya industri tekstil dan fashion, presensi limbah pada proses manufaktur merupakan salah satu hal yang tidak dapat dihindari.

Dalam industri tekstil dan fashion, terdapat dua jenis limbah yang dihasilkan yaitu limbah pra-konsumsi dan limbah pasca-konsumsi. Limbah pra-konsumsi merupakan sisa dari proses manufaktur seperti perca bahan 
sisa pemotongan atau cairan pewarna kimia sisa dari proses pewarnaan material. Sedangkan limbah pascakonsumsi dihasilkan dari oleh konsumen setelah produk tersebut digunakan dan telah berkurang nilai fungsinya sehingga tidak digunakan oleh konsumen. Limbah prakonsumsi merupakan salah satu permasalahan yang dihadapi dalam industri tekstil dan fashion saat ini. Limbah pra-konsumsi tersebut, karena tidak memiliki nilai ekonomi yang signifikan, sebagian besar berakhir di tempat pembuangan akhir (TPA) serta menambah tingkat pencemaran lingkungan apabila tidak dapat didaur-ulang. Kerugian yang diakibatkan oleh sisa limbah prakonsumsi berupa material kain oleh pabrik garmen dianggap sebagai kerugian finansial yang umum terjadi dalam proses produksi garmen. Di Indonesia, limbah pra-produksi berupa perca kain umumnya diberikan kepada pengepul yang akan menjualnya kembali pada produsen lain yang membutuhkan limbah perca tersebut untuk diolah kembali menjadi produk yang memiliki nilai jual. Limbah perca kain yang dihasilkan sebagian besar berasal dari proses pemotongan bahan sebelum memasuki proses penjahitan produk. Salah satu contohnya terdapat pada proses produksi sebuah busana dasar. Dari setiap busana yang melalui proses pemotongan pola (pattern cutting) dihasilkan limbah berupa perca atau sisa material tekstil dengan rata-rata $15 \%$ per busana sedangkan estimasi material tekstil yang digunakan dalam produksi busana pada tahun 2015 adalah sebesar 400 miliar meter. Kesimpulan akhir dari pemaparan data tersebut yaitu 15\% limbah perca atau material tekstil dari 400 miliar meter bahan yang digunakan adalah sekitar 60 miliar meter limbah perca atau sisa material teksil yang menjadi limbah prakonsumsi.

Untuk mengurangi limbah, langkah umum yang dilakukan oleh masyarakat adalah daur-ulang atau recyling. Pada kegiatan daur-ulang, limbah padat maupun cair diolah untuk digunakan pada proses manufaktur produk atau didesain kembali agar memiliki nilai fungsi dan nilai ekonomi bagi masyarakat. Namun, kegiatan daur-ulang yang dilakukan dapat memakan biaya yang lebih besar dan tidak jarang produk hasil daur-ulang tidak memiliki daya pakai dan daya tahan yang sama dengan produk sebelumnya serta memiliki harga jual yang lebih tinggi. Dalam industri tekstil dan fashion, produk hasil daur-ulang memiliki peminat yang cukup signifikan terutama bagi konsumen dari kalangan menengah ke atas dengan gaya hidup urban dan serba moderen namun peduli dengan lingkungan alam sekitarnya. Salah satu alternatif lain dalam mengurangi limbah dari industri tekstil dan fashion, terutama limbah pra-konsumsi, adalah menerapkan konsep zero waste pada proses manufaktur produk. Pada konsep zero waste, proses manufaktur dioptimalkan terutama dalam penggunaan material sehingga limbah yang dihasilkan pada tahapan tersebut 
dapat diminimalisir. Konsep ini pada tahun 2008, dikembangkan oleh sejumlah desainer fashion dan akademisi yang berpendapat bahwa limbah pra-konsumsi yaitu perca kain dari hasil pemotongan bahan dapat dihindari dengan mengoptimalkan penggunaan material dan penyesuaian pada proses desain busana agar dapat mengoptimalkan dimensi material yang digunakan. Konsep ini dalam industri tekstil dan fashion kemudian dikenal dengan nama Zero Waste Fashion Design. Salah satu alat utama dalam penerapan konsep tersebut adalah optimalisasi penggunaan teknik pattern cutting pada proses manufaktur busana. Pada hakikatnya, optimalisasi material telah dipraktekkan sejak zaman dahulu ketika teknologi pembuatan material untuk busana dan proses pembuatan busana masih terbilang sederhana. Material untuk busana, karena tingkat kesulitan dan proses pembuatan material yang sulit dan berkepanjangan, membuat masyarakat zaman dahulu lebih efektif dan efisien dalam memanfaatkan material tersebut. Tampilan visual atau bentuk dasar busana tradisional yang cenderung mengadaptasi bentuk geometris dasar merupakan salah satu contoh adanya penerapan konsep zero waste mengingat material yang dihasilkan untuk busana tersebut umumnya ditenun dengan hasil akhir dimensi material yang berbentuk geometris dasar yaitu persegi empat. Salah satu busana tradisional yang memiliki bentuk geometris dasar persegi empat adalah kimono. Desain busana kimono berasal dari negara
Jepang, dan telah menjadi busana nasional negara tersebut seperti layaknya kain kebaya di Indonesia. Sampai dengan saat ini, kimono tetap digunakan oleh masyarakat Jepang sebagai bagian dari busana formal dan non-formal. Selain sebagai busana tradisional negara tersebut, kimono telah di adaptasi dengan berbagai bentuk dan cara pakai yang lebih moderen. Bentuk dasar busana kimono sering kali digunakan sebagai inspirasi oleh desainer fashion untuk busana siap pakai (ready to wear) dan adibusana (couture) sehingga telah menjadi busana klasik yang mendunia.

\section{Batasan Masalah}

Batasan dalam penelitian ini adalah bagaimana penerapan konsep zero waste yang optimal pada busana wanita moderen dengan mengadaptasi bentuk dasar pada busana tradisional kimono. Busana yang diangkat sebagai studi kasus dibatasi pada busana tradisional karena bentuk dasar busana yang sederhana dapat meningkatkan optimalisasi penggunaan material sesuai dengan konsep zero waste. Ruang lingkup dibatasi pada busana tradisioanl dengan bentuk pola geometris dasar yaitu persegi empat yang terdapat pada busana kimono.

\section{METODE PENELITIAN}

Metode yang digunakan pada penelitian ini adalah kualitatif yang dilakukan secara deskiptif berdasarkan analisis dari kajian-kajian 
pada literatur dan hasil eksperimen yang berkaitan dengan penelitian. Analisis yang didasarkan pada kesimpulan dari hasil studi literatur yang dilakukan terhadap objek penelitian yaitu busana kimono yang memiliki bentuk dasar geometris persegi empat. Eksperimen dilakuan untuk menunjukkan potensi yang dimiliki oleh busana kimono yang diadaptasi menjadi busana moderen dengan konsep Zero Waste. Hasil akhir dari penelitian ini berupa kesimpulan atas objek penelitian berdasarkan sudut pandang peneliti.

\section{Studi Pustaka}

\section{Zero Waste Fashion Design}

Zero Waste Fashion Design dapat didefinisikan sebagai proses desain produk fashion yang tidak menghasillkan limbah atau sisa produksi dari bahan yang digunakan dengan mengoptimalkan teknik pattern cutting pada proses desain (Rissanen \& Mcquillan, 2016). Lebih lanjut, (Mcquillan, 2011) memaparkan bahwa penerapan konsep Zero Waste pada desain fashion merupakan sebuah proses yang tidak dapat diprediksi hasilnnya. Proses desain fashion dengan konsep ini lebih mengutamakan eksplorasi namun tetap menghargai karakter dan kemampuan material yang digunakan. Material yang digunakan dalam proses desain dengan konsep Zero Waste, sesuai dengan konsepnya, tidak menghasilkan limbah pasca produksi seperti kain perca dari material kain dan dapat meminimalisir proses produksi busana. Penerapan konsep zero waste telah dan tanpa disadari, dipraktekkan pada busana-busana tradisioanl di dunia (Rissanen \& Mcquillan, 2016). Keterbatasan bahanbaku dan proses produksi material kain yang berkepanjangan membuat masyarakat pada zaman dahulu lebih menghargai material untuk membuat busana sehingga pada setiap proses pembuatan busana, material digunakan seluruhnya tanpa sisa.

Rissanen dan Mcquillan (2016) memaparkan bahwa dalam zero waste fashion design, terdapat lima kriteria yang harus dipertimbangkan dalam proses desain dan produksi busana yaitu:

1. Tampilan visual. Hasil akhir dari busana harus memiliki tampilan visual yang menarik bagi konsumen.

2. Kesesuaian ukuran dan kenyamanan. Busana yang dihasilkan harus sesuai dengan ukuran konsumen dan nyaman digunakan.

3. Biaya. Busana yang dihasilkan dapat diproduksi dan dijual dengan harga yang sesuai dan terjangkau oleh target konsumen yang dituju.

4. Keberlanjutan. Busana yang dihasilkan tidak memiliki limbah pra-konsumsi dan memiliki daya tahan pakai dengan jangka waktu yang cukup lama. Harus dapat diperbaiki, di daur ulang, atau dirancag kembai menjadi busana lain. 
5. Kemudahan produksi. Busana yang dihasilkan harus dapat diproduksi secara efisien.

Selain lima kriteria di atas, Rissanen dan Mcquillan (2016) menambahkan delapan faktor yang harus dipertimbangakan sebelum proses desain dimulai sebagai berikut:

1. Tipe busana. Tentukan jenis busana yang ingin dibuat.

2. Dimensi material kain yang digunakan. Dimensi busana yang digunakan harus terukur dengan baik sebelum mulai proses desain dan produksi.

3. Jenis material yang digunakan. Menentukan jenis material yang diinginkan terutama dalam menghasilkan efek sesuai dengan konsep desain.

4. Siluet. Bentuk dasar busana.

5. Fitur tertentu yang diinginkan pada busana. Harus ditentukan pada saat proses pembuatan konsep dan desain busana agar dapat menjadi pertimbangan dalam proses produksi.

6. Bagian yang tetap dan fleksibel (dapat dirubah) pada busana. Tingkat kesulitan lebih tinggi jika terlalu banyak bagian busana yang tetap atau tidak dapat dirubah (modifikasi).

7. Konstruksi busana dan penyelesaian akhir. Menentukan detail dan penyelesaian akhir busana untuk memastika kualitas yang prima pada hasil akhir.
Faktor-faktor diatas merupakan dasar pertimbangan yang dapat dimanfaatkan untuk optimalisasi proses desain, tahapan produksi, hingga hasil akhir. Beberapa hal lain yang dapat menjadi pertimbangan adalah melakukan proses konstruksi pola busana secara runut dan teratur namun mengubah alur sesuai kebutuhan serta melakukan modifikasi bila perlu.
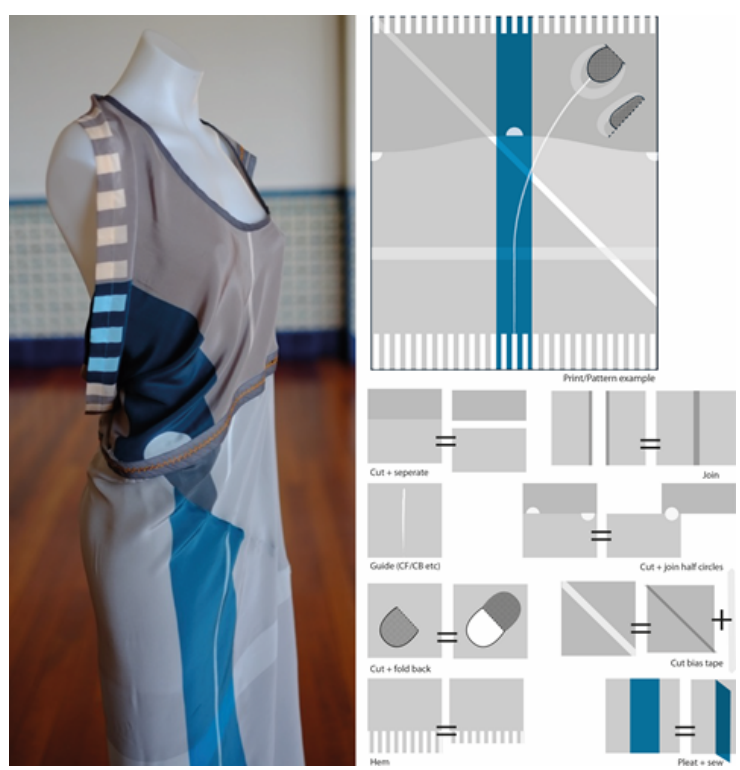

Gambar 1. Busana Dengan Konsep Zero Waste. (Rissanen, T., \& Mcquillan, H., 2016).

Zero waste merupakan sebuah konsep yang diterapkan pada industri untuk produksi masal dengan tujuan untuk mengurangi limbah yang dihasilkan pada saat proses produksi sehingga dapat mengurangi dampak pencemaran lingkungan. Secara tidak langsung, konsep zero waste telah diadaptasi pada cara manusia berbusana sejak zaman dahulu. Hal ini dapat dilihat dari bentuk bentuk busana geometris yang terdapat pada busana Yunani, Romawi, Asia dan 
India serta Timur Tengah. Busana tradisional tersebut dibuat dengan memanfaatkkan material kain dari serat alam atau kulit hewan dengan teknik tenun atau kempa. Sistem penjahitan dan penggutingan pola busana belum dikenal pada masa itu sehingga busana dibuat mengikuti dimensi material yang tersedia dan meminimalisir limbah atau sisa perca yang dihasilkan mengingat tingkat kesulitan dan waktu yang dibutuhkan untuk menghasilkan material tersebut.

\section{Definisi dan Konstruksi Kimono}

Istilah kimono mulai digunakan ketika terjadi akulturasi budaya barat dengan timur di Negara Jepang pada tahun 1845. Istilah tersebut mengacu kepada busana yang digunakan oleh masyarakat di Jepang mencakup busana tradisional untuk upacara keagamaan, kostum pertunjukan, dan berbagai macam variasi busana untuk digunakan dalam kegiatan sehari-hari (Sato, 2010).
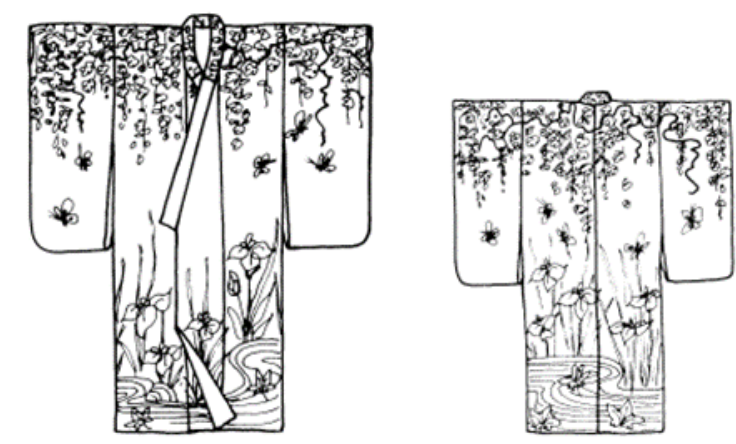

Gambar 2. Kimono Wanita. (Marshall, John, 1988).

Desain kimono secara garis besar yaitu mengoptimalkan penggunaan ruang antara tubuh manusia dan material kain yang digunakan. Berdasarkan pemaparan Ellinwood

dijelaskan bahwa konstruksi kimono adalah sebagai berikut:

"The design of the kimono maximizes the use of space between the body and the cloth. It is actually a full-length garment that is assembled from rectangular pattern pieces, with a few tucks and easements, and the sleeves appear to hang about the space around the wearer. Its construction in the same regardless of gender, overlapping in front for both men and women. For this reason, kimonos are considered gender neutral. Any gender specificity is due to colors, fabrics, and prints and not silhouette or shape. Placed flat on table, women's kimono have a slit opening in the sleeve and men's do not. The ingenious advantage of the kimono design is that the garment adjusts its size to the wearer's needs; it is truly one-size-fits-all. (Ellinwood, 2011).

Berdasarkan pemaparan Ellinwood (2011) dapat dipahami bahwa kimono merupakan busana yang dibuat dengan bentuk pola dasar persegi dengan beberapa kelonggaran dan penyesuaian. Busana kimono dapat digunakan baik pada pria dan wanita dan yang membatasinya hanya penggunaan motif serta warna pada material kain yang digunakan. 


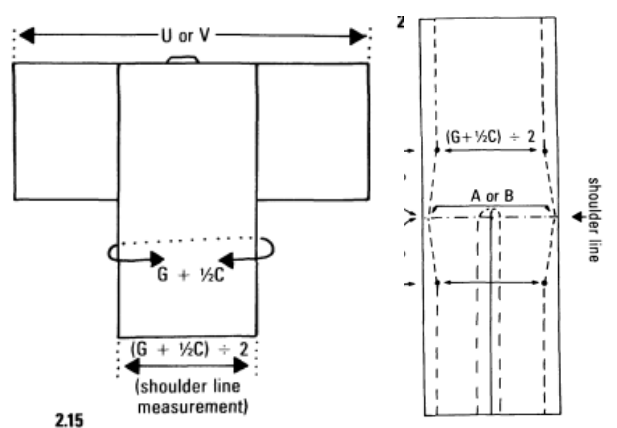

Gambar 3. Flat Pattern Kimono. (Marshall, John, 1988).

Konstruksi kimono pada dasarnya serupa baik untuk busana pria dan wanita. Salah satu kelebihan dari desain kimono adalah ukuran busana yang menyesuaikan dengan pemakainya.

\section{HASIL DAN ANALISIS}

Berdasarkan penerapan konsep zero waste dengan penentuan kriteria sebagai berikut berikut:

1. Tampilan visual yang menarik.

2. Kesesuaian ukuran.

3. Kemudahan produksi.

Dan dengan mempertimbangkan beberapa kriteria dalam proses desain yaitu:

1. Tipe Busana

2. Dimensi Material

3. Siluet

4. Fleksibilitas desain dan pola busana

5. Konstruksi busana dan finishing.

Pada busana tradisional kimono, dengan bentuk dasar persegi dapat di optimalisasi agar limbah sisa perca kain yang dihasilkan dibawah 15\%.
Hal ini dapat dilihat pada bentuk flat pattern kimono tradisional pada gambar 4 dengan lebar material 13-15 inci. Lebar material yang digunakan pada kimono tradisonal disesuaikan dengan ketersediaan material yang menjadi standar di negara Jepang.

\begin{tabular}{|ll|l|l|l|l|l|l|l|}
\hline$y_{10}$ & 1 & 1 & 1 & 1 & 1 & 1 & 1 \\
\hline 1 & 1 & 1 & 1 & 1 & 1 & & 1 \\
\hline
\end{tabular}

Gambar 4. Flat Pattern Busana Kimono Tradisional Dengan

Peletakan Memanjang. (Marshall, John, 1988).

Eksperimen yang dilakukan adalah mengadaptasi bentuk dasar dari kimono tradisional dan melakukan modifikasi desain dan cara peletakan flat pattern menggunakan dimensi material yang umum tersedi saat ini yaitu lebar kain $90 \mathrm{~cm}-150 \mathrm{~cm}$ sebagai berikut:

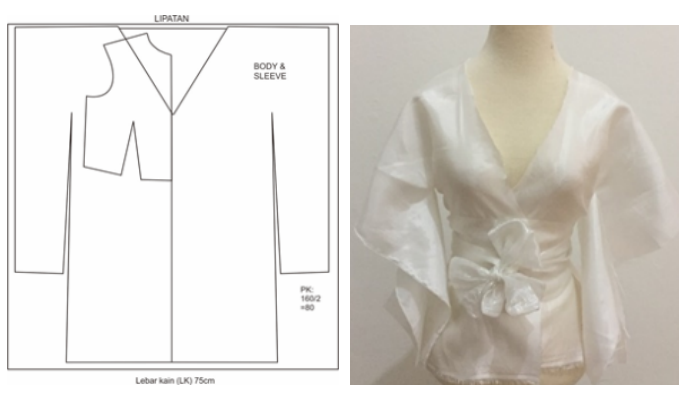

Gambar 5. Ekperimen Pertama.

(Dokumentasi Pribadi, 2017)

Kimono lengan panjang dengan bagian lengan bawah saja yang dijahit. Selain dapat dipergunakan dengan cara memakai kimono biasa, bagian depan dan lengan dapat diikatkan pada setiap sisi sehingga dapat menjadi outer dengan pita disetiap sisinya. 


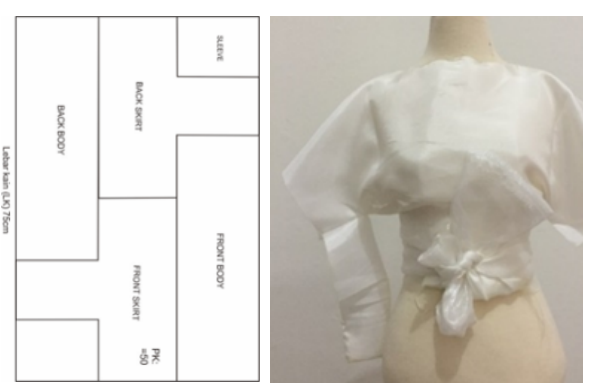

Gambar 6. Ekperimen Kedua.

(Dokumentasi Pribadi, 2017)

Adaptasi dari bentuk dasar geometris persegi pada kimono dan cara peletakan pola flat dari kimono tradisional.
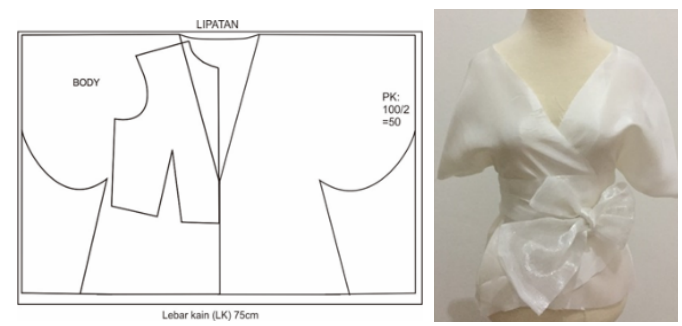

Gambar 7. Ekperimen Ketiga.

(Dokumentasi Pribadi, 2017)

Kimono berbentuk lekukan pada bagian lengan dan bentuk badan A line.

Berdasarkan hasil eksperimen ditemukan bahwa dengan mengadaptasi cara peletakan pola kain (flat pattern) pada kimono tradisional dapat diperoleh limbah perca yang hasilnya kurang dari 15\% sehingga optimalisasi material diatas 85\%. Dengan menerapkan konsep zero waste dan pertimbangan desainnya untuk menghasilkan pada busana kimono tradisional untuk memperoleh bentukan desain yang memiliki nilai kebaruan dapat dipahami bahwa:
1. Kimono moderen hasil adaptasi bentukan dari kimono tradisional memiliki tampilan visual yang menarik walaupun memiliki bentukan yang lebih sederhana.

2. Ukuran yang dihasilkan pada desain kimono moderen disesuaikan dengan ukuran tubuh pengguna dan tidak terlihat berlebihan.

3. Dalam proses eksperimen tidak ditemukan kesuliatn yang signifikan dalam memproduksi busana.

4. Tipe busana, yaitu kimono tradisional memiliki potensi untuk dimodifikasi dengan bentukan yang lebih moderen.

5. Dimensi material yang tersedia saat ini yaitu lebar kain $90 \mathrm{~cm}$ $150 \mathrm{~cm}$ memungkinkan untuk digunakan pada desain kimono moderen dengan optimalisasi pemanfaatan material diatas 85\%.

6. Siluet busana bungkus yang merupakan hasil dari bentuk pola dasar geometris persegi adalah salah satu bentuk yang memiliki potensi untuk dimodifikasi.

7. Konstruksi busana kimono dengan bentuk dasar geometris memungkinkan untuk diproduksi.

\section{KESIMPULAN}

Konsep zero waste pada umumnya diterapkan dalam industri produksi masal sebagai salah satu solusi dampak pencemaran lingkungan. Tanpa disadari konsep ini telah lama 
diterapkan pada busana tradisional namun hanya dibatasi pada cara pembuatan material dan siluet busana. Beberapa jenis busana tradisonal di dunia mengadaptasi bentuk busana sederhana yaitu bentuk geometris. Selain karena mengikuti teknik pembuatan yang umumnya ditenun, bentuk geometris dapat memenuhi kebutuhan dasar manusia berbusana serta memiliki potensi untuk dimodifikasi lebih lanjut. Salah satu busana tradisional yang sampai dengan saaat ini terus berkembang dan menjadi inspirasi desain busana moderen adalah kimono. Bentuk dasar kimono yang terdiri dari penggabungan material kain berbentuk segi empat dan secara keseluruhan memiliki siluet $\mathrm{T}$ memiliki potensi untuk dimodifikasi menjadi busana moderen yang lebih sederhana. Selain potensi tersebut, bentuk busana dasar yang geometris dapat dibuat dengan konsep zero waste sehingga mengurangi limbah perca sisa hasil produksi pada proses pemotongan busana dan mengoptimalkan pemanfatan material kain yang digunakan diatas $85 \%$.

\section{DAFTAR PUSTAKA}

(2011). Ellinwood, Janica Greennerg. Fashion by Design. (first published). United States of America: Fairchild Books.

(1988). Marshall, John. Make Your Own Japanese Clothes. Patterns and Ideas for Modern Wear. (First Edition). Tokyo \& New York: Kodansha International (2016). Rissanen, T., \& Mcquillan, H.
Zero Waste Fashion Design. London: Bloomsbury.

(2010). Sato, Caroline Jane. Regarding Fashions on The 20th Century Women's Kimono. School of Architecture and Design. Melbourne: RMIT University. 